\title{
Avaliação Ecotoxicológica de Hidrocarbonetos em Solo Tropical Utilizando Folsomia candida
}

\author{
Lara Tetzner de Souza*, Cassiana Maria Reganhan Coneglian.
}

\section{Resumo}

Um grande problema da atualidade é a contaminação do solo por hidrocarbonetos, que pode ocorrer desde o refino do petróleo, transporte e armazenamento de combustíveis, até em postos de comercialização dos mesmos, sendo este inclusive a maior porcentagem de áreas contaminadas do estado de São Paulo. O objetivo deste trabalho foi avaliar a toxicidade do resíduo de hidrocarboneto presente na borra oleosa resultante da troca de óleos de motores automotivos e da gasolina em latossolo natural, mediante teste ecotoxicológico com o organismo Folsomia candida, colêmbolo bioindicador de qualidade do solo muito utilizado em testes ecotoxicológicos para avaliar a toxicidade de substâncias no solo e os efeitos destes compostos químicos sobre os ecossistemas terrestres, como ferramenta de avaliação da qualidade do solo.

Palavras-chave: Hidrocarbonetos, ecotoxicologia de solo, Folsomia candida.

\section{Introdução}

Os conhecimentos das características do solo são importantes para o sustento dos ecossistemas e a sua qualidade pode ser avaliada mediante fatores físicos, químicos e biológicos. Dentre os fatores biológicos, os testes ecotoxicológicos têm sido utilizados para avaliar a contaminação de solos, como uma ferramenta para complementar as análises químicas. Os testes são padronizados com organismos que apresentam importante papel ecológico, como minhocas, colêmbolos e enquitreídeos. O colêmbolo Folsomia candida (Figura 1) é um invertebrado da mesofauna do solo com importante papel na decomposição da matéria orgânica, recomendado como bioindicador da qualidade do solo por organizações reguladoras ambientais.

Figura 1 - Cultivo de Folsomia candida

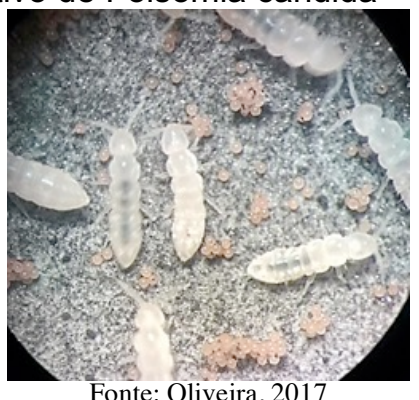

No presente projeto, utilizou-se deste organismo teste para avaliar a toxicidade de hidrocarbonetos tanto em sua forma de borra oleosa quanto de gasolina comum, comumente encontrados em áreas de solo contaminado do estado de São Paulo.

\section{Resultados e Discussão}

Os testes foram realizados de acordo com a norma ABNTNBR ISO 11267/2011. A borra oleosa foi solubilizada em latossolo tropical formando-se três fases. As fases utilizadas nos testes ecotoxicológicos foram as que apresentaram menor taxa de biodegradação no solo; e a gasolina comum, adquirida no comércio. Os testes foram realizados em Solo Artificial Tropical (SAT), de acordo com ABNT NBR 15537 (2014), em quatro repetições para cada concentração. O teste iniciou-se com 10 organismos com idades de 10 a 12 dias, mantidos durante o período de 28 dias à temperatura de $22 \pm 2^{\circ} \mathrm{C}$ e fotoperíodo de $16 \mathrm{~h} / 8 \mathrm{~h}$ (claro/escuro), sendo semanalmente alimentados e tendo a umidade corrigida. Para fins de finalização e contagem, adicionou-se aos recipientes água, e tinta de carimbo solúvel, e, por contraste, os organismos puderam ser fotografados com câmera Nikon T7. A contagem dos organismos foi realizada na fotografia por computador. Nos testes onde avaliou-se a toxicidade da borra oleosa, pôde-se verificar que a taxa de reprodução não foi afetada nas concentrações e fases no Teste 1 , apenas no Teste 2 (Tabela 1) com EC50=171,675. Contudo, no Teste 3, a toxicidade da gasolina apresentou-se aguda, com a morte de todos os organismos, incluindo os adultos.

Tabela 1. Resultados dos Testes 1 e 2 de toxicidade da borra oleosa com o organismo Folsomia candida

\begin{tabular}{|ccc|}
\hline $\begin{array}{c}\text { Conc. } \\
\text { (\%) }\end{array}$ & $\begin{array}{c}\text { Média Organismos } \\
\text { (4 réplicas) Teste 1 }\end{array}$ & $\begin{array}{c}\text { Média Organismos } \\
\text { (4 réplicas) Teste 2 }\end{array}$ \\
\hline Controle & 649 & 991 \\
$\mathbf{2 5}$ & 649 & 1176 \\
$\mathbf{5 0}$ & 684 & 1038 \\
$\mathbf{7 5}$ & 637 & 685 \\
$\mathbf{1 0 0}$ & 705 & 613 \\
\hline
\end{tabular}

Tabela 2. Resultados do Teste 3 de toxicidade da gasolina com o organismo Folsomia candida

\begin{tabular}{|cc|}
\hline Conc. $(\mathrm{mL})$ & Média Organismos (4 réplicas) \\
\hline Controle & 761 \\
$\mathbf{2}$ & 0 \\
$\mathbf{3}$ & 0 \\
$\mathbf{4}$ & 0 \\
$\mathbf{5}$ & 0 \\
& Conclusões
\end{tabular}

Nas amostras de solo solubilizado e contaminado com a borra oleosa não foi apresentado efeito tóxico aos organismos com significância estatística, entretanto, a gasolina apresentou toxicidade aguda.

\section{Agradecimentos}

Faculdade de Tecnologia da Universidade Estadual de Campinas (UNICAMP), campus I de Limeira.

ASSOCIAÇÃO BRASILEIRA DE NORMAS TÉCNICAS. NBR ISO 11267. Qualidade do solo - Inibição da reprodução de Collembola (Folsomia candida) por poluentes do solo. - Determinação de efeitos sobre reprodução e sobrevivência. Rio de Janeiro, 2011.

ASSOCIAÇÃO BRASILEIRA DE NORMAS TÉCNICAS. NBR 15537.

Ecotoxicologia terrestre - Toxicidade aguda - Método de ensaio com minhocas (Lumbricidae). Rio de janeiro, 2014.

OLIVEIRA, D. Toxicidade multigeracional do fipronil para Folsomia candida em solo natural tropical. Dissertação (Mestrado em Tecnologia - Área Ambiente). Universidade Estadual de Campinas, Faculdade de Tecnologia, 2017. 